\title{
The use of the bispectral index in the detection of pain in mechanically ventilated adults in the intensive care unit: A review of the literature
}

\author{
Robin Marie Coleman RN MSc ${ }^{1,2}$, Yannick Tousignant-Laflamme PT PhD ${ }^{3}$, Paul Ouellet PhD ${ }^{4}$, \\ Élizabeth Parenteau-Goudreault PT MSc ${ }^{3}$, Jennifer Cogan $\mathrm{MD}^{5}$, Patricia Bourgault RH PhD ${ }^{2}$
}

RM Coleman, Y Tousignant-Laflamme, P Ouellet, É ParenteauGoudreault, J Cogan, P Bourgault. The use of the bispectral index in the detection of pain in mechanically ventilated adults in the intensive care unit: A review of the literature. Pain Res Manag 2015;20(1):e33-e37.

BACKGROUND: Pain assessment is an immense challenge for clinicians, especially in the context of the intensive care unit, where the patient is often unable to communicate verbally. Several methods of pain assessment have been proposed to assess pain in this environment. These include both behavioural observation scales and evaluation of physiological measurements such as heart rate and blood pressure. Although numerous validation studies pertaining to behavioural observation scales have been published, several limitations associated with using these measures for pain assessment remain. Over the past few years, researchers have been interested in the use of the bispectral index monitoring system as a proxy for the evaluation of encephalography readings to assess the level of anesthesia and, potentially, analgesia.

OBJECTIVES: To synthesize the main studies exploring the use of the bispectral index monitoring system for pain assessment, to guide future research in adults under sedation in the intensive care unit.

METHOD: The EMBASE, Medline, CINAHL and PsycINFO databases were searched for studies published between 1996 and 2013 that evaluated the use of the bispectral index in assessing pain.

RESULTS: Most studies conclude that nociceptive stimulation causes a significant increase in the bispectral index and revealed the importance of controlling certain confounding variables such as the level of sedation.

DISCUSSION: Further studies are needed to clearly demonstrate the relationship between nociceptive stimuli and the bispectral index, as well as the specificity of the bispectral index in detecting pain.

Key Words: Bispectral index; Intensive care; Nociceptive stimuli; Pain; Pain assessment

Self-report of pain with tools, such as the visual analogue scale, is the gold standard in pain assessment among patients with intact cognitive, linguistic and social functions (1-5). However, self-report is not relevant in unconscious patients in the intensive care unit (ICU), where these functions are often impaired. Therefore, in this context, heteroassessment of pain becomes the only available option to correctly identify the presence of pain. Heteroassessment is possible through observation of behavioural components (6) or physiological signs of pain (7). Certain behavioural scales of pain, such as the Critical Care Pain Observation Tool and the Behavioral Pain Scale $(8,9)$, are commonly used. On the other hand, behavioural scales also have some shortcomings that limit their use in certain clinical

\section{L'utilisation de l'index bispectral pour déceler} la douleur chez des adultes sous ventilation mécanique à l'unité de soins intensifs : une analyse bibliographique

HISTORIQUE : Il est extrêmement difficile pour les cliniciens d'évaluer la douleur, surtout à l'unité de soins intensifs, où le patient est souvent incapable de communiquer verbalement. Plusieurs méthodes d'évaluation de la douleur ont été proposées dans ce contexte, y compris des échelles d'observation comportementale et l'évaluation de mesures physiologiques comme la fréquence cardiaque et la tension artérielle. Malgré la publication de nombreuses études de validation des échelles d'observation comportementale, plusieurs limites sont liées à leur utilisation pour évaluer la douleur. Depuis quelques années, les chercheurs s'intéressent à l'utilisation du système de monitorage de l'index bispectral pour remplacer l'évaluation des lectures encéphalographiques afin d'estimer le niveau d'anesthésie et, potentiellement, d'analgésie.

OBJECTIFS : Synthétiser les principales études sur l'utilisation d'un système de monitorage de l'index bispectral pour évaluer la douleur afin d'orienter les futures recherches chez les adultes sous sédation à l'unité de soins intensifs.

MÉTHODOLOGIE : Les chercheurs ont fait des recherches dans EMBASE, Medline, CINAHL et PsycINFO afin d'en extraire les études sur l'utilisation de l'index bispectral pour évaluer la douleur, publiées entre 1996 et 2013.

RÉSULTATS : La plupart des études ont conclu que la stimulation nociceptive entraîne une augmentation significative de l'index bispectral et ont révélé l'importance de contrôler certaines variables confusionnelles, telles que le niveau de sédation.

EXPOSÉ : D'autres études s'imposent pour démontrer clairement le lien entre un stimulus nociceptif et l'index bispectral, ainsi que la spécificité de l'index bispectral à déceler la douleur.

contexts such as reduced muscular activity induced by drugs or certain diseases that limit body movement $(8-10)$. Furthermore, there is a potential for bias associated with observer judgment (8-10).

It is recognized that not all physiological measures, especially vital signs, are specific to pain because they can be influenced by factors related to stress or by the administration of drugs (eg, sedatives, opioids, vasoactive agents) $(8,10,11)$. This lack of specificity of vital signs in detecting pain greatly limit their use and support the exploration of other, potentially more specific physiological indicators of pain (10-13).

Considering that the integration of nociception and pain occurs through different cortical centres, some authors have explored the

\footnotetext{
${ }^{1}$ Centre hospitalier universitaire de Sherbrooke, Direction interdisciplinaire des services cliniques, Direction des soins infirmiers; ${ }^{2}$ École des sciences infirmières, Faculté de médecine et des sciences de la santé; ${ }^{3}$ École de réadaptation, Faculté de médecine et des sciences de la santé, Université de Sherbrooke, Sherbrooke, Québec; ${ }^{4}$ Réseau de santé Vitalité, New Brunswick; ${ }^{5}$ Institut de Cardiologie de Montréal, Université de Montréal, Montréal, Québec

Correspondence: Dr Patricia Bourgault, École des sciences infirmières, Faculté de médecine et des sciences de la santé, Université de Sherbrooke, 27-4016, 3001 12e Avenue Nord, Sherbrooke, Quebec J1H 5N4. Telephone 819-820-6868 ext 12885, e-mail patricia.bourgault@usherbrooke.ca
}

OPEN ACCESS

This open-access article is distributed under the terms of the Creative Commons Attribution Non-Commercial License (CC BY-NC) (http:// creativecommons.org/licenses/by-nc/4.0/), which permits reuse, distribution and reproduction of the article, provided that the original work is properly cited and the reuse is restricted to noncommercial purposes. For commercial reuse, contact support@pulsus.com 


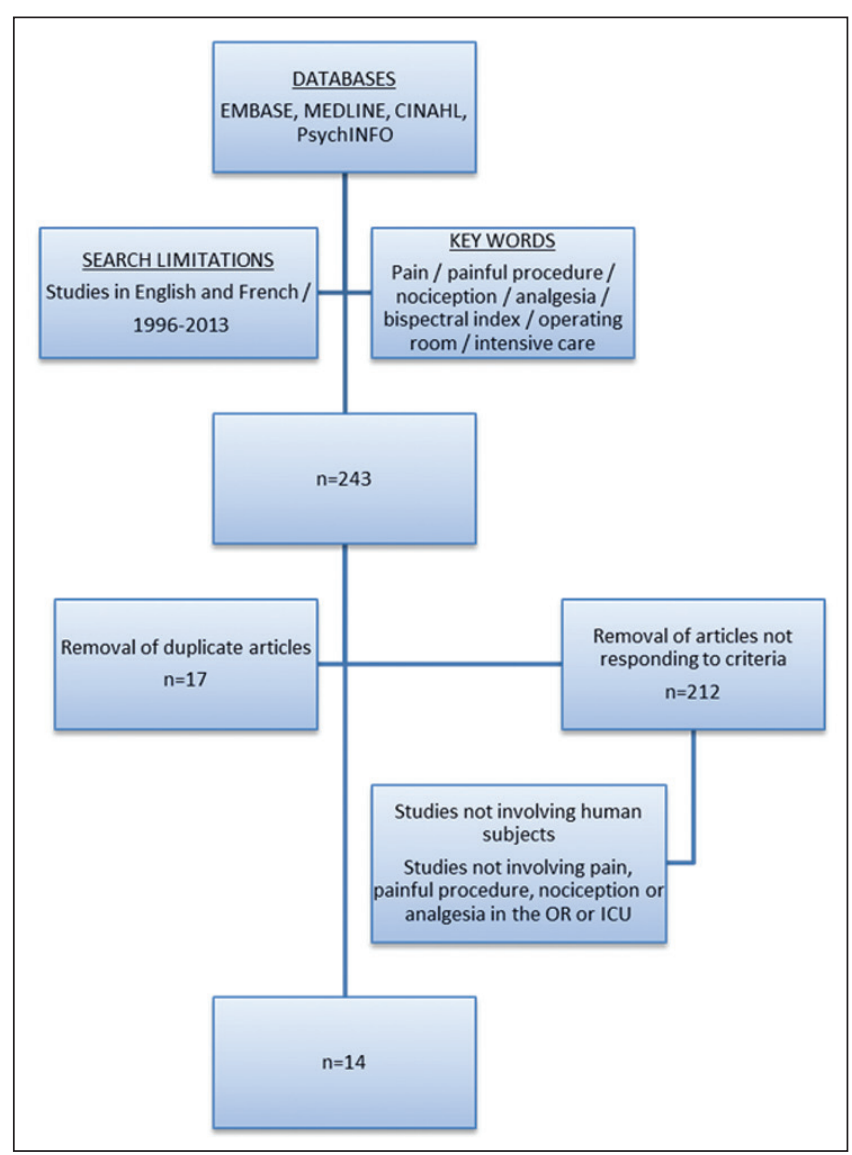

Figure 1) Selection of articles flow chart diagram. ICU Intensive care unit; OR Operating room

use of measuring brain activity to detect the presence of pain in patients (14). There are currently two more commonly used methods to measure cortical activity - the bispectral index (BIS) (BIS Monitor, Covidien, USA) and the entropy monitor (Datex-Ohmeda Division, Instrumentarium Corp, Finland). However, the present review focuses strictly on the role of the BIS monitor, not only because of its wider utilization in clinical settings, but because it has also been much more thoroughly studied than entropy in assessing levels of analgesia and pain. In addition, these two technologies are highly correlated (15-17). Throughout the past decade, studies have demonstrated the relevance of use of the BIS in monitoring the level of sedation in the context of the ICU (18). Furthermore, several studies demonstrate a potential link between the BIS value and nociceptive procedures (19-21), which suggest that the BIS could help detect the presence of nociception in association with the behavioural assessment of pain in patients undergoing mechanical ventilation and sedation.

The BIS is a physiological index that provides a value calculated from a proprietary algorithm that interprets cortical activity (electroencephalography) and activity of the corrugator supercilii muscle (electromyography [EMG]). The BIS is derived from a noninvasive technology that provides a composite value of cortical activity between 0 (no cortical activity) and 100 (completely awake) using electrodes placed on the frontal and temporal areas. A BIS value between 40 and 60 is considered to represent a state of general anesthesia, whereas the 60 to 80 range represents sedation. Several patients in the ICU are under the effect of sedation (range 60 to 80 ) without being in a state of general anesthesia (eg, small doses of intravenous propofol or fentanyl) (13).

Cortical activity generates waves between $0 \mathrm{~Hz}$ and $50 \mathrm{~Hz}$, and several other sources of electrical activity generate waves such as the EMG activity of the corrugator supercilii muscle (22). EMG activity is expressed in the range from $37 \mathrm{~Hz}$ to $300 \mathrm{~Hz}$. Furthermore, between $37 \mathrm{~Hz}$ and $50 \mathrm{~Hz}$, there is an overlap between the cortical activity and EMG activity that could influence the received signal. Because the BIS monitor captures a wide range of electrical activity $(0 \mathrm{~Hz}$ to $300 \mathrm{~Hz})$, the algorithm interprets electrical activity $>70 \mathrm{~Hz}$ as a noncortical activity related to the EMG. The strength of this EMG signal is expressed in decibels and displayed on the BIS monitor (22). The calculated value of the BIS represents the weighted sum of power spectral parameters, burst suppression and frequency domain of the electroencephalogram (23). When a patient is under the influence of general anesthesia, the desired range of BIS is between 40 and 60 because this range ensures a low probability of explicit memories (ie, perioperative memories) and response to a nociceptive stimulus (22).

The objective of the present review was to synthesize the scientific literature on the potential role of BIS in assessing pain. The strengths and weaknesses in relation to this measure will be highlighted to guide future research in sedated adults in the ICU.

\section{METHODS}

Four databases were searched for the present review of the literature: EMBASE, Medline, CINAHL and PsycINFO. The present review aims to evaluate the use of the BIS monitor in assessing pain. The keywords used were: pain, painful procedure, nociception or analgesia, bispectral index, operating room and intensive care. The search was limited to articles published in English or French between 1996 and 2013. This electronic database search strategy yielded 243 records. From the 243 studies obtained, 17 duplicate records were identified and removed, leaving 226 unique articles. These articles were thereafter screened for eligibility determination and inclusion criteria, resulting in the removal of 212 articles that did not involve human subjects, painful procedures, nociception or analgesia in the operating room (OR) or ICU setting. All articles remaining after this process $(n=14)$ were selected and analyzed in the present review by the first author (RMC) (Figure 1). These studies focused on the use of the BIS monitor to assess pain or nociception and were divided into two main groups: studies conducted in the OR ( $\mathrm{n}=9$ studies) and those conducted in the ICU ( $\mathrm{n}=5$ studies).

\section{RESULTS}

Studies of the BIS in the assessment of nociception and level of analgesia in the context of anesthesia in the OR

The studies leading up to the approval of the clinical use of BIS in monitoring the depth of anesthesia suggest that the BIS value increases in response to a nociceptive stimulus (21). Indeed, it has been shown that nociceptive stimulus induces specific facial expressions of pain (24). Therefore, the increase in the myoelectrical activity of the facial muscles, especially the corrugator supercilii muscles, may be a good indicator of pain. Following these findings, some researchers studied the link between experimental and clinical nociceptive stimuli, various anesthetics and analgesics and the BIS value. Table 1 summarizes the main results of studies on the use of BIS in the assessment of pain and level of analgesia in patients under general anesthesia $(15,16,19-21,25-28)$. This summary shows that studies performed in the context of general anesthesia in the OR generally indicate an association between nociceptive stimuli and increases in the BIS value.

Some variables can affect changes in BIS during nociceptive stimulation. These include the administration of opioids (which decrease BIS by reducing cortical activity) (20), the minimum alveolar concentration of sevoflurane (decreases BIS when minimum alveolar concentration is $>1.3$ by reducing cortical activity) (21) and the administration of neuromuscular blocking agents (NMBA) (decreases BIS by reducing EMG activity) (29). Furthermore, considering that patients in the OR were under the influence of general anesthesia, it is arguable that the increase of the BIS value in response to a nociceptive stimulus may be attenuated because 
TABLE 1

The use of the bispectral index (BIS) in the assessment of nociception and level of analgesia in the context of anesthesia in the operating room

\begin{tabular}{|c|c|c|c|c|}
\hline Study & Principal aim & Population & BIS monitor & Result \\
\hline $\begin{array}{r}\text { Sebel et al, } \\
1997(19)\end{array}$ & $\begin{array}{l}\text { Explore the utility of BIS to guide anesthesia by } \\
\text { observing motor response to surgical incision }\end{array}$ & $\begin{array}{l}\mathrm{n}=300 \text {; noncranial elective } \\
\text { surgery requiring } \\
\text { surgical incision } \geq 2.5 \mathrm{~cm}\end{array}$ & Version 1.1 & $\begin{array}{l}\text { BIS significantly predicted patient response to } \\
\text { surgical incision, but the response was } \\
\text { influenced by the primary anesthetic agent } \\
\text { used. The administration of opioids } \uparrow \text { the level of } \\
\text { sedation and } \downarrow \text { BIS. Reduction in BIS varied } \\
\text { according to the opioid administered }\end{array}$ \\
\hline $\begin{array}{l}\text { Lysakowski } \\
\text { et al, } 2001 \\
(20)\end{array}$ & $\begin{array}{l}\text { Measure the influence of different concentrations of } \\
\text { several opioids given in conjuction with a fixed dose } \\
\text { of propofol in relation to the loss of consciousness }\end{array}$ & $\begin{array}{l}\mathrm{n}=75 \text {; elective surgery } \\
\text { under general } \\
\text { anesthesia }\end{array}$ & Version 1.1 & $\begin{array}{l}\text { As the dose of opioid increased, the BIS value at } \\
\text { loss of consciousness increased (demonstrating } \\
\text { the sedative effect of opioids) }\end{array}$ \\
\hline
\end{tabular}

(20) of propofol in relation to the loss of consciousness and BIS values during induction of anesthesia

Ekman et Assess the ability of the BIS to demonstrate the effects

al, 2004 of an increase of sevoflurane concentration with and

(21) without a nociceptive stimulation (laryngoscopy)

Takamatsu Measure the validity of BIS and entropy measures to

et al, 2006 predict nociception (electrical stimulus of $20 \mathrm{~mA}, 40 \mathrm{~mA}$,

(15) $\quad 60 \mathrm{~mA}$ and $80 \mathrm{~mA}$ ) during sevoflurane anesthesia

Hans et al, Assess the effect of rocuronium (NMBA) on BIS during $n=25$; elective surgery

2006 (25) a nociceptive stimulation (laryngoscopy for $20 \mathrm{~s}$ ) under general anesthesia

Dierckens Study BIS variations in response to nociceptive $n=14$; intestinal surgery by

et al, 2007 stimulations (incision, surgical spreaders, cleaning

(16) and wound closure)

Sandin et Compare BIS variations in two nociceptive stimulations: $n=10$; healthy volunteers

al, 2008 TENS and cold water arm immersion general anesthesia

(26)

Ellerkmann Compare $\mathrm{CVI}$ and BIS before and after a noxious

et al, 2013 stimuli under changing remifentanil concentrations (28)

Coleman et Describe changes in BIS in response to experimental

al, 2013 noxious stimuli of moderate (40/100) and severe

(27) (70/100) intensities. Examine the sensitivity and

specificity of BIS in distinguishing noxious stimuli of

$\mathrm{n}=21$; elective knee

surgery under general

anesthesia

$\mathrm{n}=40$; elective

Version 4.0 BIS significantly $\uparrow$ following nociceptive

stimulation, but $\downarrow$ after having doubled

sevoflurane concentration

Version 3.12 Under sevoflurane, BIS $\uparrow$ significantly when the intensity of the nociceptive stimulus was increased

Version 4.0 The nociceptive stimulation (laryngoscopy) $\uparrow$ BIS scores with and without NMBA

n/a BIS tended to $\uparrow$ during nociceptive stimulations, but no significant variation

Version XP BIS $\uparrow$ significantly during the nociceptive stimulation but the MAC influenced BIS variation during the nociceptive stimulation

$\mathrm{n}=25$; elective surgery under general anesthesia

$\mathrm{n}=30$; elective surgery under general

anesthesia
Version 4.1 BIS $\uparrow$ significantly during the nociceptive stimulation

Version 3.20 BIS $\uparrow$ significantly during both moderate and severe noxious stimuli. The sensitivitiy and specificity were weak in distinguishing different pain intensities at deep sedation levels

$\downarrow$ Decreased; $\uparrow$ Increased; CVI Composite Variability Index; MAC Minimal alveolar concentration; n/a Not available; NMBA Neuromuscular blocking agents; TENS Transcutaneous electrical nerve stimulation

cortical activity is significantly reduced in these conditions. Additionally, it is plausible to suggest that changes in BIS may be more indicative or sensitive to the presence of pain in the context of the ICU, where patients are not under general anesthesia.

Studies of the BIS in the assessment of pain and level of analgesia in the ICU

The use of the BIS in the ICU raises some questions that have not yet been examined in the literature. A central point comes from the fact that the algorithm indicating the BIS values associated with different levels of sedation and anesthesia was established in patients under general anesthesia. This questions the internal validity of using the BIS algorithm for monitoring in the context of the ICU.

A few studies on the use of BIS in pain assessment have been conducted specifically in the ICU with sedated and mechanically ventilated patients. Table 2 summarizes the results of these studies $(11,13,17,29,30)$. The studies in the ICU demonstrate an increase in the BIS value during routine nociceptive procedures (stimuli), such as endotracheal suctioning $(11,13,30)$ and mobilization (13). Some studies also show that an analgesic treatment (opioids) counteracts this increase in the BIS $(11,13,30)$. Possible explanations are that opioids cause a reduction in the BIS by inducing an analgesic effect (pain reduction) or by causing a sedative side effect. In addition, some studies have shown the importance of controlling factors that appear to influence the BIS value during painful stimuli such as the level of sedation and administration of NMBA (29).

\section{DISCUSSION}

The assessment of pain in ICU patients unable to communicate verbally remains a significant challenge for clinicians. The use of an objective and valid measure that can detect or even quantify pain behaviour would be highly useful in adjusting the level of analgesia for these patients and would help to obtain optimal pain relief. The BIS monitor is a promising tool that is currently under investigation for a potential new indication. Several studies have evaluated its relevance in the assessment of pain in patients unable to communicate verbally. However, scientific evidence is not yet sufficient to conclude on the validity of the BIS in assessing pain.

Most studies conclude that nociceptive stimulation causes a significant increase in BIS. Although BIS could appear to be sensitive in detecting nociception, it remains to be demonstrated whether this increase is sufficiently specific to be clinically useful in pain assessment in the context of the ICU. Furthermore, there is a lack of studies containing detailed medication used among subjects (sedation, analgesia and NMBA). It would be important to further document these potential confounding factors. Another major weakness of studies conducted in the ICU is the lack of correlational analyses between the results of the BIS and EMG. A particularly interesting issue was raised by Arbour et al (31), which should be considered in future studies. In their study, which involved 40 subjects ( 21 men and 19 women), they observed that women showed higher EMG interference than men. This observation may indicate potential sex differences in BIS reactivity, which may explain the observed variability of the results (31). 
TABLE 2

The use of the bispectral index (BIS) in the assessment of pain and level of analgesia in the intensive care unit

\begin{tabular}{|c|c|c|c|c|}
\hline Study & Principal aim & Population & BIS monitor & Result \\
\hline $\begin{array}{l}\text { Brocas et al (30), } \\
2002\end{array}$ & $\begin{array}{l}\text { Evaluate changes in BIS during a nociceptive procedure } \\
\text { (endotracheal suction). Assess the impact of a dose of } \\
\text { alfentanil on BIS during endotracheal suction }\end{array}$ & $\mathrm{n}=11$ SMVP & Version 3.03 & $\begin{array}{l}\text { BIS } \uparrow \text { was significantly higher during } \\
\text { endotracheal suction in the absence of opioid } \\
\text { administration (alfentanyl) than with opioid } \\
\text { administration }\end{array}$ \\
\hline $\begin{array}{l}\text { Vivien et al (29), } \\
2003\end{array}$ & $\begin{array}{l}\text { Determine the extent of the decrease in BIS following } \\
\text { administration of NMBA }\end{array}$ & $\mathrm{n}=45$ SMVP & Version 2.1 & $\begin{array}{l}\text { BIS and EMG } \downarrow \text { significantly following } \\
\text { administration of NMBA }\end{array}$ \\
\hline Li et al (11), 2009 & $\begin{array}{l}\text { Compare BIS during a nociceptive procedure (mobilization } \\
\text { or endotracheal suction) and a non-nociceptive } \\
\text { procedure (light touch on the shoulders and feet) }\end{array}$ & $\mathrm{n}=48$ SMVP & Version XP & $\begin{array}{l}\text { BIS } \uparrow \text { significantly during a nociceptive } \\
\text { procedure }\end{array}$ \\
\hline $\begin{array}{l}\text { Haenggi et al (17), } \\
2008\end{array}$ & $\begin{array}{l}\text { Assess the usefulness of BIS to predict the response to } \\
\text { sedative and analgesic medication during a painful } \\
\text { procedure (intratracheal suction) }\end{array}$ & $\mathrm{n}=44$ SMVP & $\mathrm{n} / \mathrm{a}$ & $\begin{array}{l}\text { BIS } \uparrow \text { more after a nociceptive stimulus without } \\
\text { an analgesic medication than with an analgesic } \\
\text { medication }\end{array}$ \\
\hline $\begin{array}{l}\text { Gélinas et al (13), } \\
2011\end{array}$ & $\begin{array}{l}\text { Describe BIS values at rest and during two nociceptive } \\
\text { procedures (mobilization and endotracheal suction) }\end{array}$ & $\mathrm{n}=9$ SMVP & Version 3.20 & $\begin{array}{l}\text { BIS } \uparrow \text { significantly during both nociceptive } \\
\text { procedures }\end{array}$ \\
\hline
\end{tabular}

$\downarrow$ Decrease; $\uparrow$ Increase; n/a Not available; NMBA Neuromuscular blocking agents; SMVP Sedated and mechanically ventilated patients

As well, although the BIS may be clinically useful, none of these studies provide a practical method for using the BIS in the clinical context. However, studies show the importance of controlling certain confounding variables in future research including the administration of certain drugs such as anesthetics, opioids and NMBA.

Because the clinical context of the ICU is very different from the OR, using the current BIS algorithm for pain detection or control in patients sedated and mechanically ventilated in the ICU is questionable, considering that the level of sedation is generally lower than in the OR.

The present literature review justifies the need to further study the validity of the BIS monitor in the assessment of pain in the ICU by incorporating the EMG value in the analysis and interpretation of this physiological measurement. Thus, further studies in the ICU

\section{REFERENCES}

1. Kehlet H, Jensen T, Wollf C. Persistent postsurgical pain:

Risk factors and prevention. Lancet 2006;367:1618-25.

2. Pasero C. Pain in the critically ill patient. J Perianesth Nursing 2003;18:422-5.

3. Kaarola A, Pettila V, Kekki P. Quality of life six years after intensive care. Intens Care Med 2003;29:1294-9.

4. Turk D, Melzack R, eds. Handoook of Pain Assessment, 3rd edn. New York: The Guilford Press; 2011.

5. Dunwoody C, Krenzischeck D, Pasero C, Rathmell J, Polomano R. Assessment, physiological monitoring, and consequences of inadequately treated acute pain. J Perianesth Nurs 2008;23(Suppl 1A):s15-s27.

6. Craig K, Patrick C. Facial expression during induced pain. J Pers Soc Psychol 1985;48:1080-91.

7. Tousignant-Laflamme Y, Bourgault P, Gélinas C, Marchand S. Assessing pain behaviors in healthy subjects using the critical-care pain observation tool (CPOT): A pilot study. J Pain 2010;11:983-7.

8. Payen J, Bru O, Bosson J, et al. Assessing pain in critically ill sedated patients by using a behavioral pain scale. Crit Care Med 2001;29:2258-63.

9. Gélinas C, Johnston C. Pain assessment in the critically III ventilated adult: Validation of the critical-care pain observation tool and physiologic indicators. Clin J Pain 2007;23:497-505.

10. Gélinas C, Arbour C. Behavioral and physiologic indicators during a nociceptive procedure in conscious and unconscious mechanically ventilated adults: Similar or different? J Crit Care 2009;24:628.e7-17.

11. Li D, Miaskowski C, Burkhardt D, Puntillo K. Evaluations of physiologic reactivity and reflexive behaviours during noxious procedures in sedated critically ill patients. J Crit Care 2009;24:472.e9-13.

12. Arbour C, Gélinas C. Are vital signs valid indicators for the assessment of pain in postoperative cardiac surgery ICU adults? Intensive Crit Care Nurs 2010;26:83-90.

13. Gélinas C, Tousignant-Laflamme Y, Tanguay A, Bourgault P. Exploring the validity of the bispectral index, the critical-care pain observation tool and vital signs for the detection of pain in sedated and mechanically ventilated critically ill adults: A pilot study. Intensive Crit Care Nurs 2011;27:46-52. population are needed to determine the specificity of the BIS in detecting pain in a clinical setting as well as to demonstrate whether that property is clinically significant enough to support its use in the ICU. ICU studies must include detailed information pertaining to pharmacology (sedation, analgesia, NMBA) and perhaps consider the influence of new agents, such as dexmedetomidine, on BIS that have not been extensively studied.

ACKNOWLEDGEMENTS: This work was supported by grants from the Quebec Pain Research Network (QPRN), the Quebec Nursing Intervention Research Network (RRISIQ) and the Centre de recherche clinique of the CHUS (CRC-CHUS). Patricia Bourgault and Yannick Tousignant-Laflamme are supported members of the CRC-CHUS.

14. Treede R, Apkarian A, Bromm B, Greenspan J, Lenz F. Cortical representation of pain: Functional characterization of nociceptive areas near the lateral sulcus. Pain 2000;87:113-9.

15. Takamatsu I, Ozaki M, Kazama T. Entropy indices vs the bispectral index for estimating nociception during sevoflurane anaesthesia. Br J Anaesth 2006;96:620-6.

16. Dierckens E, Fleyfel M, Robin E, et al. Is entropy a monitor for the guidance of intraoperative analgesia? Ann Fr Anesth Reanim 2007;26:1138.

17. Haenggi M, Ypparila-Wolters H, Bieri C, et al. Entropy and bispectral index for assessment of sedation, analegesia and the effects of unpleasant stimuli in critically ill patients: An observational study. Critical Care 2008;12:R119.

18. LeBlanc JM, Dasta JF, Kane-Gill SL. Role of the bispectral index in sedation monitoring in the ICU. Ann Pharmacother 2006;40:490-500.

19. Sebel PS, Lang E, Rampil IJ, et al. A multicenter study of bispectral electroencephalogram analysis for monitoring anesthetic effect. Anesth Analges 1997;84:891-9.

20. Lysakowski C, Dumont L, Pellegrini M, Clergue F, Tassonyi E. Effects of fentanyl, alfentanil, remifentanil and sufentanil on loss of consciousness and bispectral index during propofol induction of anaesthesia. Br JAnaesth 2001;86:523-7.

21. Ekman A, Brudin L, Sandin R. A comparison of bispectral index and rapidly extracted auditory evoked potentials index responses to noxious stimulation during sevoflurane anesthesia. Anesth Analges 2004;99:1141-6.

22. Kelley S, ed. Monitoring Consciousness Using the Bispectral Index During Anesthesia: A Pocket Guide for Clinicians, 2nd edn. Colorado: Covidien, 2007.

23. Rosow C, Manberg PJ. Bispectral index monitoring. Anesthesiol Clin North America 2001;19:947-66.

24. Prkachin KM. Assessing pain by facial expression: Facial expression as nexus. Pain Res Manag 2009;14:53-8.

25. Hans P, Giwer J, Brichant J, Dewandre P, Bonhomme V. Effect of an intubation dose of rocuronium on spectral entropy and bispectral index responses to larygoscopy during propofol anaesthesia. Br J Anaesth 2006;97:842-7. 
26. Sandin M, Thorn S, Dahlqvist A, Wattwil L, Axelsson K, Wattwill M. Effects of pain stimulation on bispectral index, heart rate and bllod pressure at different minimal alveolar concentration values of sevoflurane. Acta Anaesthesiol Scand 2008;52:420-6.

27. Coleman RM, Tousignant-Laflamme Y, Gélinas C, et al. Changes in the bispectral index in response to experimental noxious stimuli in adults under general anesthesia. ISRN Pain 2013;1:1-8.

28. Ellerkmann RK, Grass A, Hoeft A, Soehle M. The response of the composite variability index to a standardized noxious stimulus during propofol-remifentanil anesthesia. Anesthes Analges 2013;116:580-8.

29. Vivien B, Di Maria S, Ouattara A, Langeron O, Coriat P, Riou B. Overestimation of bispectral index in sedated intensive care unit patients revealed by administration of muscle relaxant. Anesthesiology 2003;99:9-17.

30. Brocas E, Dupont H, Paugam-Burtz C, Servin F, Mantz J,

Desmonts JM. Bispectral index variations during tracheal suction in mechanically ventilated critically ill patients: Effect of an alfentanil bolus. Intens Care Med 2002;28:211-3.

31. Arbour R, Waterhouse J, Seckel MA, Bucher L. Correlation between the sedation-agitation scale and the bispectal index in ventilated patients in the intensive care unit. Heart Lung 2009;4:336-45. 


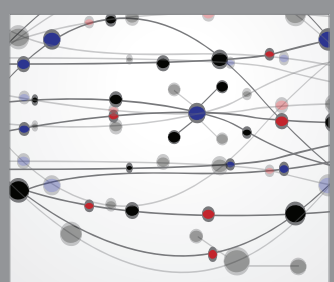

The Scientific World Journal
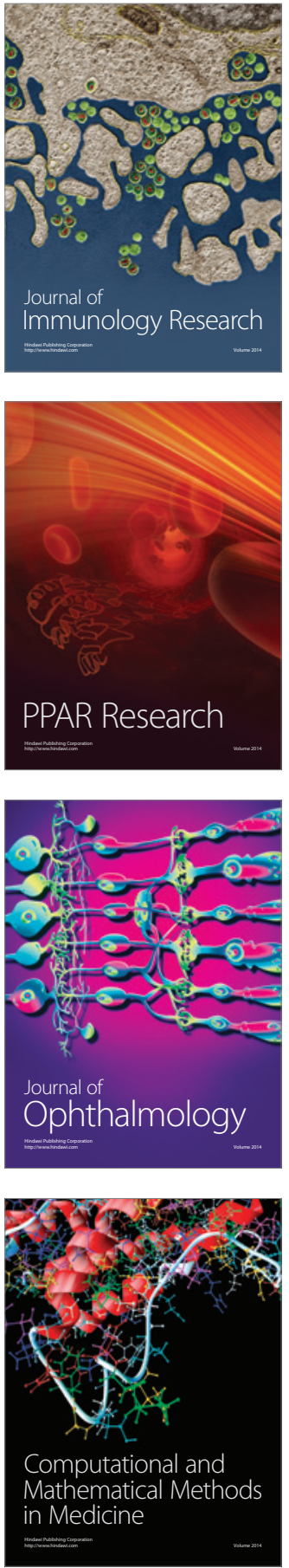

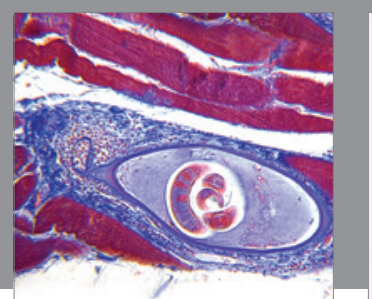

Gastroenterology Research and Practice

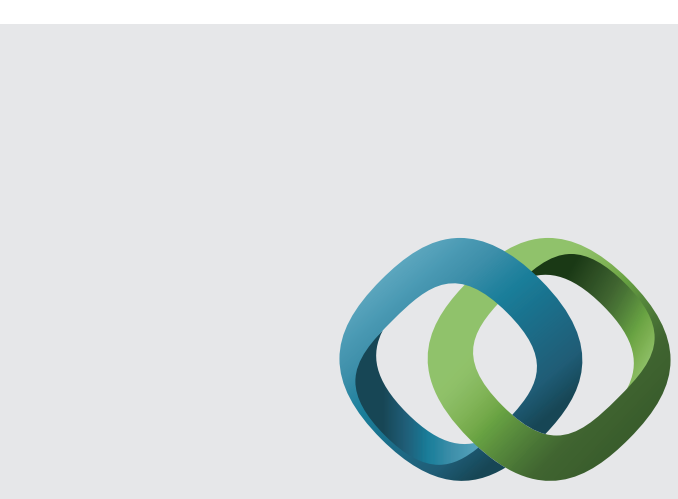

\section{Hindawi}

Submit your manuscripts at

http://www.hindawi.com
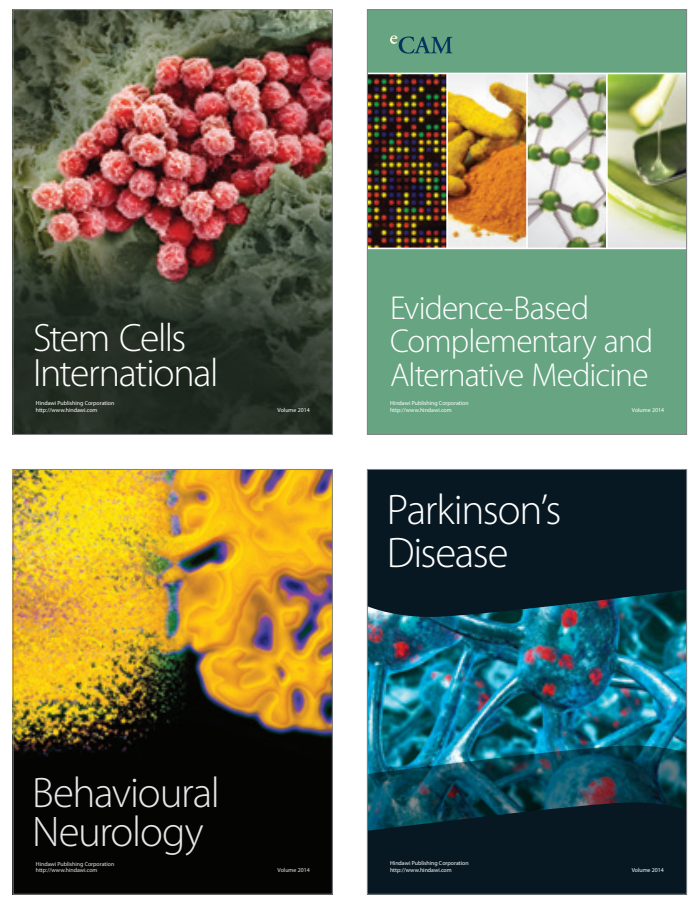
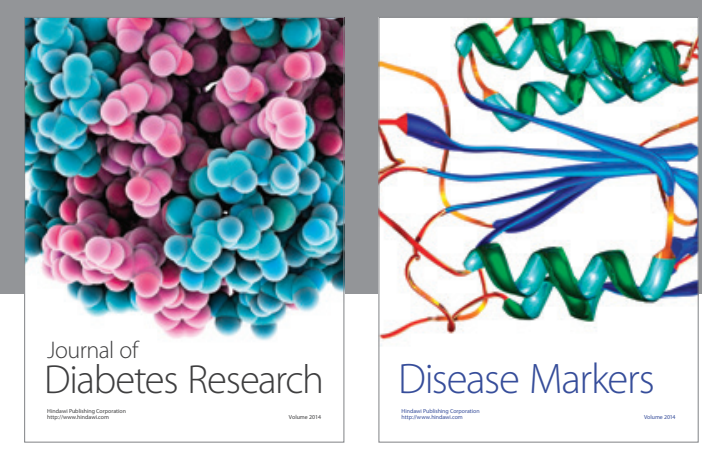

Disease Markers
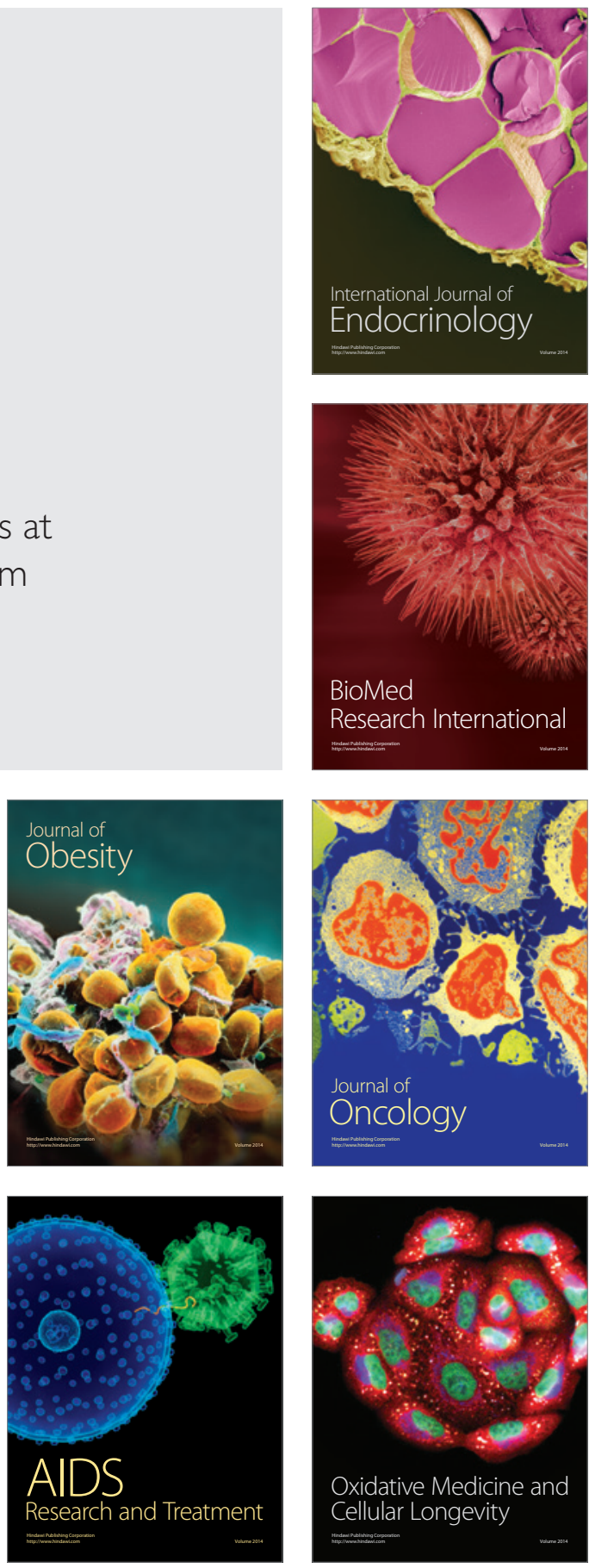